\title{
Extensive hybridization with minimal introgression in Mytilus galloprovincialis and M. trossulus in Hokkaido, Japan
}

\author{
Pamela M. Brannock*, David S. Wethey, Thomas J. Hilbish \\ Department of Biological Sciences, University of South Carolina, 715 Sumter Street, Columbia, South Carolina 29208, USA
}

\begin{abstract}
Species in the Mytilus edulis complex (M. edulis, M. galloprovincialis and M. trossulus) hybridize in nature but, depending on the species pair involved, hybridization can range from minimal to very common with extensive introgression. Since $M$. galloprovincialis has been introduced within the geographic range of $M$. trossulus in several locations, this system provides the opportunity to determine whether the propensity for hybridization and the resulting level of introgression depends upon environmental circumstances in which the 2 species become sympatric. Contact between these 2 species on the Northeast Pacific coast and within the Puget Sound results in low levels of hybridization with little to no introgression. The present study examines the level of hybridization and introgression between M. galloprovincialis and M. trossulus around Hokkaido, Japan, where these species are also sympatric. We show that 2 independent hybrid zones exist in Hokkaido, each having distinct genetic architectures. The hybrid zone formed along the northern coast of Hokkaido is similar in structure to those reported in the northeast Pacific. The second hybrid zone formed along the southern coast of Hokkaido differs markedly from these other hybrid zones by exhibiting an exceptionally high propensity for hybridization, but, like other hybrid zones between these 2 species, it generates minimal levels of introgression. The mechanism(s) producing high levels of hybridization between $M$. galloprovincialis and $M$. trossulus in southern Hokkaido may include some form of apparent outcrossing or hybrid vigor for survival but not for fertility.
\end{abstract}

KEY WORDS: Mytilus galloprovincialis $\cdot$ Mytilus trossulus $\cdot$ Hybridization $\cdot$ Northwest Pacific Resale or republication not permitted without written consent of the publisher

\section{INTRODUCTION}

Hybridization is a prevalent feature in the organization of biological diversity with as much as $18 \%$ of species hybridizing in nature (Mallet 2005). Many cases of hybridization have been attributed to species invasions and other forms of ecological disturbances (Grant 1971, Avise 2004). Whether these invasions and disturbances were intentional or accidental, they have allowed contact between species that were previously allopatric. The degree to which hybridization takes place in nature varies greatly. Hybridization can range from a rare to a common occurrence and, depending on the fitness of the $F_{1}$ and other hybrids, may result in little to extensive introgression (Avise 2004). In some cases, the level of hybridization that occurs between 2 species depends upon the environmental circumstances in which they become sympatric (Grant 1971).

In the marine environment, hybridization among species in the Mytilus edulis complex has been well documented. Commonly known as blue mussels, this complex consists of 3 species ( $M$. edulis, $M$. galloprovincialis and $M$. trossulus) that have a worldwide distribution (McDonald et al. 1991, Seed 1992) and hybridize where they co-occur. M. edulis and M. galloprovincialis are the 2 more closely related of the 3 species (Rawson \& Hilbish 1995). These 2 species hybridize readily and form hybrid swarms in several locations in the northeast Atlantic, despite strong selection acting on these individuals. Selection in this area typically favors M. galloprovincialis alleles (Gardner \& Skibinski 1988, Wilhelm \& Hilbish 1998, Bierne 
et al. 2002). In addition, Rawson \& Hilbish (1998) showed that hybridization between these species has led to extensive asymmetric introgression of mitochondrial genomes.

In contrast, Mytilus edulis and M. trossulus have levels of hybridization that depend on location. These 2 species are sympatric and hybridize in the northwest Atlantic (Comesaña et al. 1999, Rawson et al. 2001, Riginos \& Cunningham 2005) and within the Baltic Sea (Riginos \& Cunningham 2005, Kijewski et al. 2006). In the northwest Atlantic, hybridization between these species is less than $30 \%$ (Comesaña et al. 1999, Riginos \& Cunningham 2005), $F_{1}$ hybrids are rare (Rawson et al. 2001) and backcrossed individuals tend to favor $M$. trossulus alleles (Riginos \& Cunningham 2005). Furthermore, evidence of reduced fertilization success when interspecific mating occurs between these 2 species has been reported in the northwest Atlantic (Rawson et al. 2003). In the Baltic, on the other hand, a high level of introgression occurs between $M$. edulis and $M$. trossulus; individuals with gentoypes consistent with either of the pure species or $F_{1}$ hybrids are rare and backcrossed individuals contain a preponderance of M. edulis alleles (Riginos \& Cunningham 2005, Kijewski et al. 2006).

Mytilus galloprovincialis is highly invasive and has been reported as one of the top 100 invasive species of the world (Lowe et al. 2000). Native to the Mediterranean, the Black Sea and the eastern Atlantic, M. galloprovincialis has successfully invaded Australia (Daguin \& Borsa 2000, Hilbish et al. 2000), South Africa (Grant \& Cherry 1985), Chile (Daguin \& Borsa 2000), California (McDonald \& Koehn 1988), the Puget Sound (Anderson et al. 2002) and Asia (Wilkins et al. 1983, Lee \& Morton 1985, McDonald \& Koehn 1988, Suchanek et al. 1997, Skurikhina et al. 2001). M. galloprovincialis has been widely introduced through transport in ship ballast water (Carlton 1992, Geller et al. 1994) and for aquaculture purposes (Heath et al. 1995). Repeated introductions of $M$. galloprovincialis into different portions of the range of $M$. trossulus provide the opportunity to test the hypothesis that the propensity to hybridize and the consequent levels of introgression depend upon the environment. In the northeastern Pacific, separate introductions of $M$. galloprovincialis to California and the Puget Sound have led to the formation of 2 hybrid zones with low levels of hybridization and little introgression (Rawson et al. 1999, Anderson et al. 2002). A third contact zone between these species occurs in northern Japan, but this area has not been examined closely. Previous research has indicated that both $M$. galloprovincialis and M. trossulus co-occur in northern Japan (Inoue et al. 1997, Suchanek et al. 1997) and the western Sea of Japan (Skurikhina et al. 2001) and are capable of hybridizing
(Inoue et al. 1997), but the extent of the hybrid zone and the level of hybridization are unknown. The present study examines whether the pattern of hybridization between M. galloprovincialis and M. trossulus in northern Japan is similar to that observed in other geographic locations where these species hybridize. Here we show that contact between M. galloprovincialis and M. trossulus has produced 2 independent hybrid zones in northern Japan and there are extraordinary levels of hybridization in one of these hybrid zones compared to other regions where these species are sympatric.

\section{MATERIALS AND METHODS}

Mytilus edulis complex individuals were collected from 9 sites around the island of Hokkaido, Japan, in July 2004 and 25 sites in May 2006 (see Table 1). Shosanbetsu (SHO) was the only site from 2004 that was not resampled in 2006. Mussels were all collected from intertidal locations, with one exception, Akkeshi, where mussels were collected from both intertidal and subtidal habitats. Once collected, mussels were measured from anterior to posterior ends and separated into $5 \mathrm{~mm}$ size classes. A piece of the mantle edge tissue was dissected from mussels $>10 \mathrm{~mm}$ in length and preserved in $95 \%$ ethanol, while individuals $\leq 10 \mathrm{~mm}$ in length were preserved whole. Total cellular DNA was extracted following the protocol in Rawson et al. (1999) with DNA resuspended in 25 to $150 \mu$ of $\mathrm{dH}_{2} \mathrm{O}$ depending on pellet size.

Extracted DNA was assayed utilizing 3 PCR-based nuclear genetic markers. Reactions were performed in $12.5 \mu \mathrm{l}$ volume containing $1 \times$ buffer, $0.2 \mathrm{mM}$ dNTP, $1.5 \mathrm{mM} \mathrm{MgCl}_{2}, 0.3 \mu \mathrm{M}$ of each primer, 0.5 units of $T a q$ polymerase (Promega) and $1 \mu$ DNA. The first marker utilized primers Me 15 and Me 16 (Inoue et al. 1995) to amplify the $5^{\prime}$ end of the polyphenolic adhesive protein gene (Glu-5'). Thermal cycler conditions consisted of initial denaturation at $94^{\circ} \mathrm{C}$ for 1 min followed by an incubation of 30 cycles at $92^{\circ} \mathrm{C}$ for $30 \mathrm{~s}, 53^{\circ} \mathrm{C}$ for $60 \mathrm{~s}$ and $75^{\circ} \mathrm{C}$ for $60 \mathrm{~s}$ with a final primer extension for $5 \mathrm{~min}$ at $75^{\circ} \mathrm{C}$. This reaction produces size-specific banding patterns that distinguish Mytilus galloprovincialis and $M$. trossulus alleles (Inoue et al. 1995). The second marker targeted the internal transcribed spacer (ITS) region utilizing primers stated in Heath et al. (1995). Amplification consisted of the same conditions as Glu-5' except for the annealing step, which was changed to $51^{\circ} \mathrm{C}$ for $30 \mathrm{~s}$. Since the PCR products from this reaction are equal in length for both $M$. galloprovincialis and $M$. trossulus, a restriction enzyme digest was performed to obtain restriction profiles that differentiate between $M$. galloprovincialis and $M$. trossulus alleles (Rawson et al. 1996). The third nuclear 
marker amplified the Mytilus anonymous locus-I $(M A L-I)$ using the primers reported in Rawson et al. (2001). Thermal cycler parameters consisted of initially denaturing samples at $94^{\circ} \mathrm{C}$ for $2 \mathrm{~min}$, followed by an incubation of 30 cycles at $94^{\circ} \mathrm{C}$ for $30 \mathrm{~s}, 51^{\circ} \mathrm{C}$ for $30 \mathrm{~s}$ and $72^{\circ} \mathrm{C}$ for $3 \mathrm{~min}$, with a final primer extension for 5 min at $72^{\circ} \mathrm{C}$. Since this marker also produces equal length PCR product for both species, a restriction enzyme digest was performed to produce species-specific restriction fragment profiles (Rawson et al. 2001). DNA products were visualized on a $2 \%$ agarose gel containing $0.08 \mu \mathrm{g} \mathrm{ml}^{-1}$ ethidium bromide.

The 3 molecular markers used in the present study were assumed to represent single-copy nuclear gene loci and to be diagnostically differentiated between Mytilus galloprovincialis and M. trossulus. The Glu-5' marker was originally described by Inoue et al. (1995) and Rawson et al. (1996a) who showed that it is a single locus marker and is diagnostically differentiated among allopatric reference populations of $M$. galloprovincialis and $M$. trossulus. Subsequent studies have confirmed that there are no shared alleles at this locus between these 2 species except in areas where the 2 hybridize (Rawson et al. 1999, Toro et al. 2004, Braby \& Somero 2006). The $M A L-I$ locus was developed by Rawson et al. (1996b) and Southern analysis indicated that the marker is single copy. Rawson et al. (1996b, 1999) found that there were no alleles at Mal-I shared between allopatric populations of $M$. galloprovincialis and $M$. trossulus. The ITS locus was developed by Heath et al. (1995) and is shown to distinguish M. galloprovincialis and $M$. trossulus in allopatric populations. Heath et al. (1995) found that ITS behaves as a single Mendelian locus in the progeny of test crosses between $M$. edulis $\times M$. trossulus $\mathrm{F}_{1}$ hybrids and $M$. edulis, despite the fact that rDNA is generally multicopy (see discussion in Heath et al. 1995). Subsequent studies have confirmed that ITS is diagnostically differentiated among allopatric populations of $M$. galloprovincialis and $M$. trossulus and segregation of alleles at this locus in hybrid populations is consistent with that of a single-copy nuclear locus (Rawson et al. 1999, Anderson et al. 2002, Braby \& Somero 2006).

Individuals were genotyped at each locus separately and then assigned to 1 of 4 genealogical classes: Mytilus galloprovincialis, $M$. trossulus, $\mathrm{F}_{1}$ hybrid and other hybrid genotypes. Only individuals who were successfully genotyped at all 3 nuclear loci were assigned to one of these classes. $M A L-I$ and ITS did not amplify as readily as did Glu-5' despite repeated attempts and, consequently, the results reported for each gene locus separately may contain different sample sizes (see Table 1). Individuals were classified as M. galloprovincialis or $M$. trossulus if they were homozygous at all 3 loci for alleles diagnostic of each respective species. Individuals were classified as $\mathrm{F}_{1}$ hybrids if they were heterozygous for alleles from each of the 2 species at all 3 loci. The final category of other hybrids consisted of individuals that exhibited multilocus genotypes that do not fit into the 3 other categories. These individuals were assumed to be the progeny of hybrid crosses beyond $F_{1}$ hybrid (e.g. backcrosses and $\mathrm{F}_{2}$ ). We recognize that there is error in assigning individuals into distinct genealogical classes in this fashion. For example, among individuals which are heterozygous at all 3 diagnostic loci, the majority probably belongs to the $F_{1}$ genealogical class, but this genotypic category may also contain a fraction of individuals that belong to $\mathrm{F}_{2}$ and first- and second-generation genealogical classes (Nason \& Ellstrand 1993). The probability of misclassification depends upon the true genealogical composition of a population but is generally small. We have ignored this source of error in the initial description of this hybrid zone. Unless otherwise specified, the term 'hybrids' refers to the combined genealogical classes of $F_{1}$ hybrids and other hybrids.

A G-test of independence (Sokal \& Rohlf 1995) was used to determine whether there were significant differences in allele frequencies at the same site for all 3 loci, between years at the same site for all 3 loci, and for different size classes at the same site in the same year at each locus. When examining size classes, the ends of the distribution were condensed with neighboring size classes until the total number of individuals in the size class equaled or exceeded 10. Internal size classes were not combined. This procedure was first performed on the Glu-5' locus data and the resulting size classes remained consistent for the other 2 loci. Only sites containing more than 2 size classes were tested for significance. Goodness-of-fit G-tests (Sokal \& Rohlf 1995) were performed for each locus at each location to determine whether genotype frequencies differed from Hardy-Weinberg equilibrium (HWE). For populations where samples were collected in both years, separate significance tests were performed for each collection year. Populations where the allele frequency for both alleles ranged from 0.1 to 0.9 were tested. No significance tests were performed on populations if the total sample size was $<20$ individuals. For all statistical tests, $\alpha$ was set at 0.05. A Bonferroni correction (Rice 1989) was applied to all significance tests.

\section{RESULTS}

The geographical distributions of Mytilus galloprovincialis, $M$. trossulus and their hybrids around the island of Hokkaido were similar in 2004 and 2006 (Figs. 1 \& 2, respectively). M. galloprovincialis individuals dominated the western coast of Hokkaido with 
only a small proportion of $M$. trossulus alleles (8\%) present at SHO in 2004. The northern coast of the island was largely comprised of $M$. galloprovincialis individuals except at Abashiri (AB) and the inner portion of Lake Notoro (LNI), where populations contained large proportions of $M$. trossulus and hybrid individuals, respectively, and very few M. galloprovincialis individuals. Mussel populations at the mouth (LNM) and just outside (LNO) of Lake Notoro were comprised of mostly M. galloprovincialis individuals, 74 and $72 \%$ respectively, and only contained at most $5 \%$ hybrids ( $\mathrm{F}_{1}$ and other hybrids), while the LNI population mainly contained hybrid individuals $(64 \%$ in 2004 and $62 \%$ in 2006). Mussel populations on the southern coast of Hokkaido contained high frequencies of hybrid individuals ranging from $58 \%$ at Toyako Town (TY) to $82 \%$ at Shoya (SY) in 2004 (Figs. 1 \& 2). Populations on the western portion of this coast contained high proportions of M. galloprovincialis individuals compared to M. trossulus. East of Cape Erimo (near SY), however, the frequency of hybrid and $M$. galloprovincialis individuals decreased greatly and populations at Akkeshi (intertidal, AI; subtidal, AS) and Nemuro (NE) were dominated by $M$. trossulus individuals.

The majority of the hybrid individuals along both the northern and southern coast had $\mathrm{F}_{1}$ hybrid genotypes, but there was also a low frequency of individuals with genotypes characteristic of other hybrids. The frequency of other hybrids was greater among populations on the southern coast of Hokkaido compared to populations on the northern coast, but individuals with other hybrid genotypes were never common (Figs. $1 \& 2$ ). The greatest frequency of other hybrids observed was only $17 \%$ at Muroran (MR). Numerous populations exhibited significant departures from HWE (Table 1). Populations along the southern coast generally had significant excesses of heterozygous individuals, while populations on the northern coast had significant deficiencies of heterozygous individuals

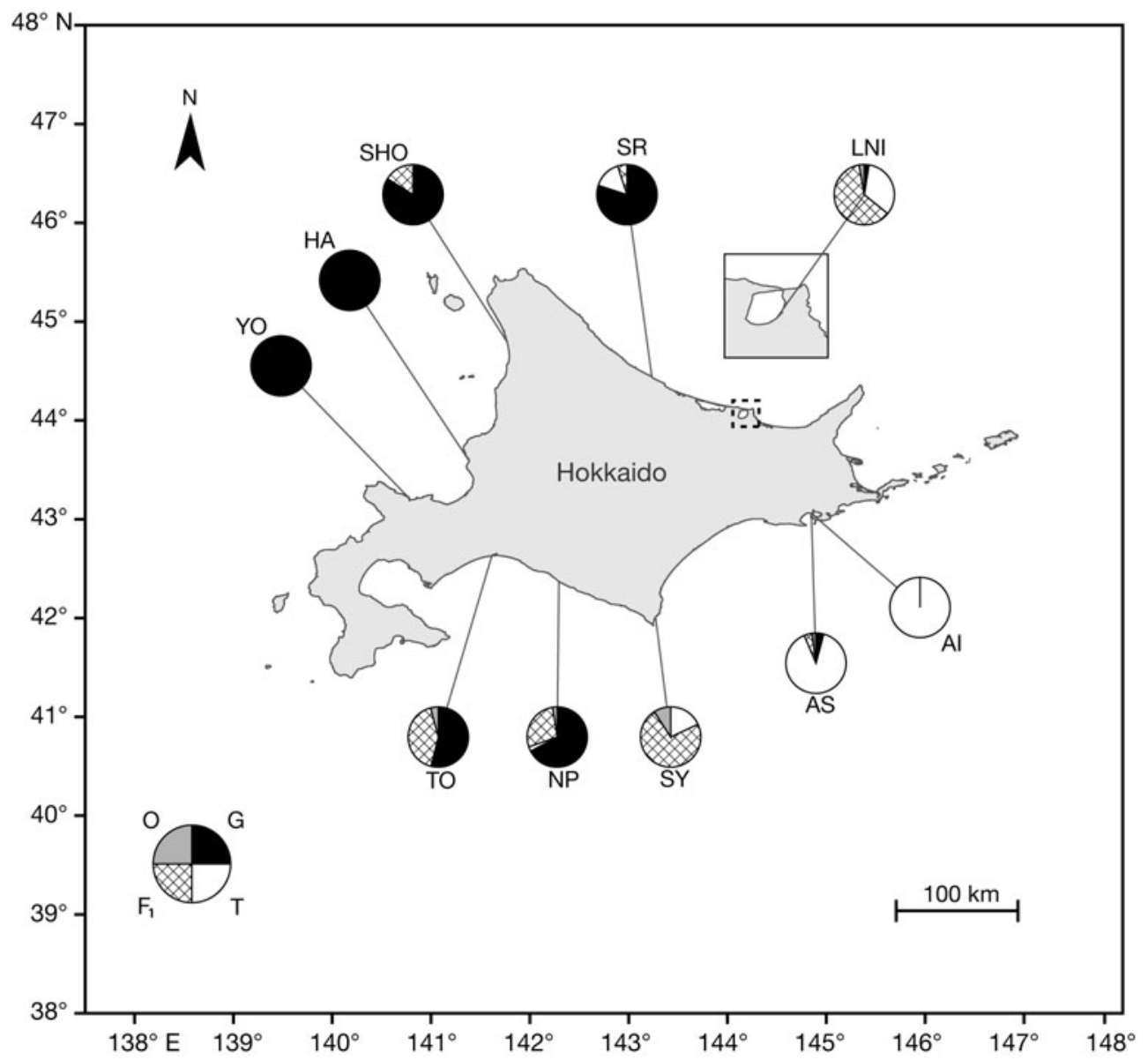

Fig. 1. Mytilus galloprovincialis and M. trossulus. Distribution in 2004 of homozygous M. galloprovincialis (black, G), homozygous $M$. trossulus (white, T), $F_{1}$ hybrid (cross-hatched, $F_{1}$ ) and other hybrid (gray, O) individuals around the island of Hokkaido, Japan. Data represent a multi-locus composite of genotypes from 3 nuclear PCR assays (Glu-5', ITS and MAL-I). Site names and codes are listed in Table 1 
(Table 1). LNI was the only site on the northern coast that deviated from this trend: this population contained a significant excess of heterozygous individuals at all 3 loci in 2004 and only at the Glu-5' locus in 2006.

Saruru (SR) and Niikappu (NP) were the only populations that had significant differences in allele frequencies between the 2 collection years. Both populations had significantly higher proportions of Mytilus galloprovincialis alleles in 2004 at all 3 loci in comparison to 2006 ( $p<0.001)$. When we compared allele frequencies between years within comparable size classes, the differences between years remained significant at both sites. Since we observed a significant difference between the 2 collection years at these 2 sites, all data collected for both years were kept separate. There was no significant difference in allele frequency among the 3 loci at any site in either year.

In 2004 there were no significant allele frequency differences among size classes for any locus at any location. In 2006 some locations displayed significant differences in allele frequencies among size classes. In the south, Toi (TI) and TY showed significant differences in allele frequency in reference to size (Table 2). TI showed significantly fewer Mytilus galloprovincialis alleles at both 0 to $5 \mathrm{~mm}$ and 10 to $15 \mathrm{~mm}$ size classes but only at Glu-5' and ITS. TY showed a significantly higher frequency of $M$. galloprovincialis alleles within the 10 to $20 \mathrm{~mm}$ size classes, but only at ITS. In the north, LNI, LNO, Utoro (UT), Sarufutsu (SA) and SR had significantly greater proportions of $M$. galloprovincialis alleles among smaller size classes (Table 2). LNO and SR showed higher proportions of M. galloprovincialis alleles in individuals $<10 \mathrm{~mm}$, while UT and SA showed this same trend in individuals $<15 \mathrm{~mm}$. The LNI population displayed significantly fewer $M$. galloprovincialis alleles in individuals 20 to $35 \mathrm{~mm}$ in length. Individuals $<20 \mathrm{~mm}$ in length were not found at LNI. All of these sites showed similar significant differences at all 3 loci, except at SA where the difference was only significant at the Glu-5' locus.

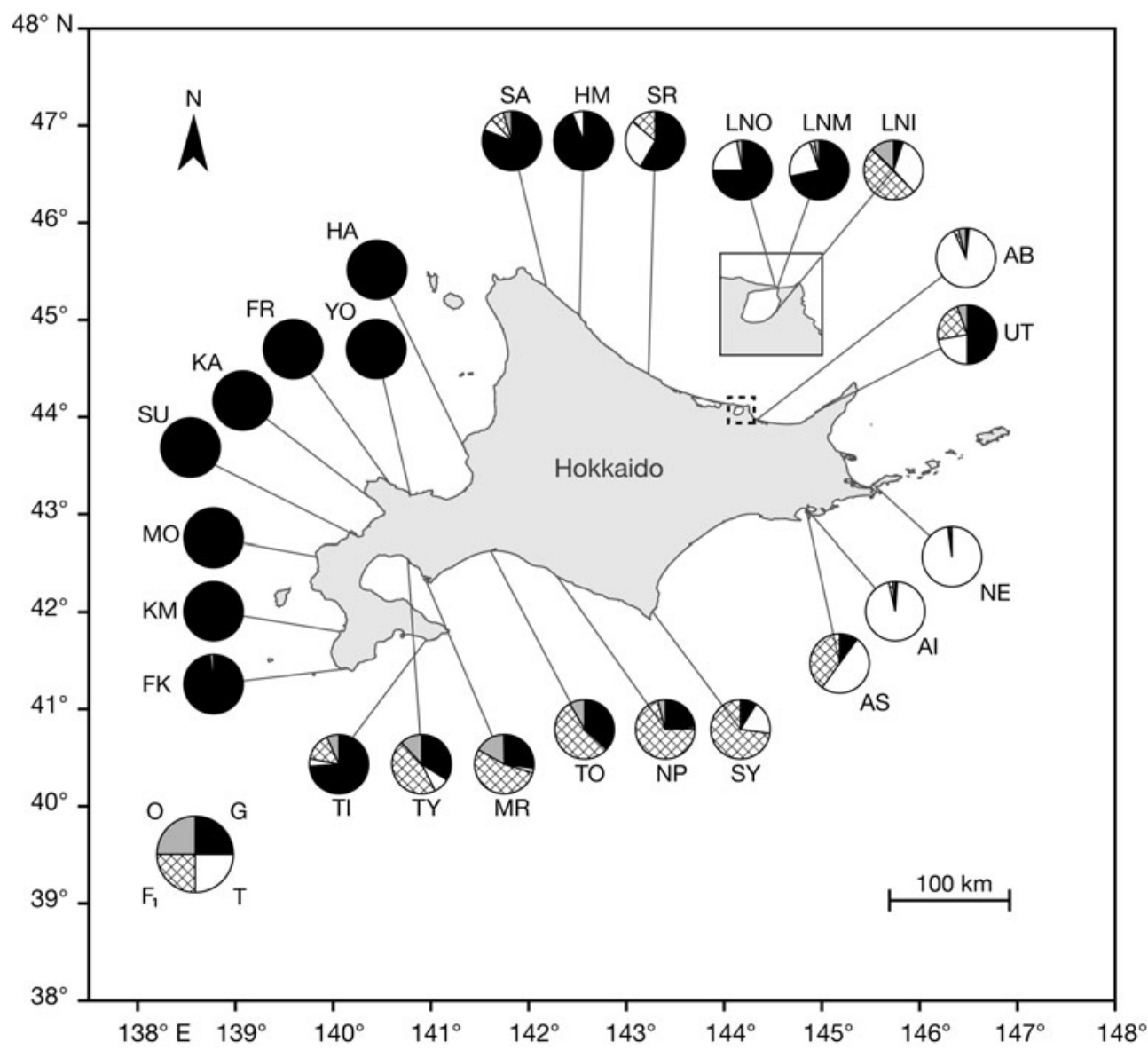

Fig. 2. Mytilus galloprovincialis and M. trossulus. Distribution in 2006 of homozygous Mytilus galloprovincialis (black, G), homozygous $M$. trossulus (white, T), $F_{1}$ hybrid (cross-hatched, $F_{1}$ ) and other hybrid (gray, O) individuals around the island of Hokkaido, Japan. Data represents a multi-locus composite of genotypes from 3 nuclear PCR assays (Glu-5', ITS and MAL-I). Site names and codes are listed in Table 1 


\section{DISCUSSION}

Mytilus galloprovincialis dominates the western portion of Hokkaido within the Sea of Japan, while $M$. trossulus is only common in samples from eastern Hokkaido. Hybridization occurs along both the northern and southern coast of the island where both species come into contact (Figs. 1 \& 2). Hybrid populations on the northern and southern coasts have considerably different genetic structures. There is a relatively smooth genetic cline along the southern coast, with western populations composed almost exclusively of $M$. galloprovincialis individuals and eastern populations com- posed almost solely of $M$. trossulus individuals. Within this cline, the frequency of hybrid individuals $\left(F_{1}\right.$ and other hybrids) often exceeds $50 \%$. In contrast to the relatively smooth genetic cline in southern Hokkaido, hybrid mussel populations in northern Hokkaido form a mosaic pattern with radical shifts in genetic composition over small distances, especially near the eastern portion of the coast (Fig. 2). Hybridization levels along the northern coast of Hokkaido almost never exceed $15 \%$, except at LNI where $>60 \%$ of the population were hybrids in both sample years (Figs. $1 \& 2$ ).

The Kuril Island chain extends off the eastern coast of Hokkaido (Fig. 3) and appears to separate the north-

Table 1. Mytilus edulis complex. Sample sizes (n) and genotype frequencies for Glu-5', MAL-I and ITS loci for populations collected around Hokkaido, Japan, in July 2004 (10 populations) and May 2006 (25 populations). Only populations containing hybrid individuals were tested for goodness-of-fit to Hardy-Weinberg equilibrium (HWE). GG: mussels homozygous for $M$. gallprovincialis alleles; TG: mussels containing both $M$. galloprovincialis and $M$. trossulus alleles; TT: mussels homozygous for M. trossulus alleles. -: population was not tested for HWE. Significant departures from HWE $(p<0.05)$ are indicated by an asterisk $\left({ }^{*}\right.$, for significant excess) or a star $(\star$, for significant deficiency). ns: the sample did not significantly ( $p>0.05)$ depart from HWE

\begin{tabular}{|c|c|c|c|c|c|c|c|c|c|c|c|c|c|c|c|c|c|}
\hline & \multirow[t]{2}{*}{ Site } & \multirow{2}{*}{$\begin{array}{l}\text { Abbre- } \\
\text { viation }\end{array}$} & \multicolumn{5}{|c|}{ Glu-5' } & \multicolumn{5}{|c|}{$-I T S$} & \multicolumn{5}{|c|}{$M A L-I$} \\
\hline & & & $\mathrm{n}$ & GG & TG & TT I & HWE & $\mathrm{n}$ & GG & TG & $\mathrm{TT}$ & HWE & $\mathrm{n}$ & GG & TG & TT 1 & HWE \\
\hline \multicolumn{18}{|l|}{2004} \\
\hline \multirow[t]{3}{*}{ West } & Shosanbetsu & SHO & 29 & 86.2 & 13.8 & 0 & - & 28 & 85.7 & 14.3 & 0 & - & 28 & 83.3 & 16.7 & 0 & - \\
\hline & Hamamasu & HA & 7 & 85.7 & 0 & 14.3 & - & 6 & 100 & 0 & 0 & - & 6 & 100 & 0 & 0 & - \\
\hline & Yoichi Cape & $\mathrm{YO}$ & 51 & 100 & 0 & 0 & - & 51 & 100 & 0 & 0 & - & 51 & 100 & 0 & 0 & - \\
\hline \multirow[t]{5}{*}{ South } & Tomakomai & $\mathrm{TO}$ & 50 & 56 & 42 & 2 & ns & 50 & 56 & 38 & 6 & ns & 50 & 56 & 44 & 0 & ns \\
\hline & Niikappu & NP & 43 & 67.4 & 30.2 & 2.3 & ns & 43 & 69.8 & 20.9 & 9.3 & ns & 43 & 67.5 & 30.2 & 2.3 & ns \\
\hline & Shoya & SY & 11 & 0 & 81.8 & 18.2 & - & 11 & 0 & 72.7 & 27.3 & - & 11 & 0 & 81.8 & 18.2 & - \\
\hline & Akkeshi subtidal & AS & 49 & 4.1 & 8.2 & 87.8 & - & 49 & 4.1 & 4.1 & 91.8 & - & 49 & 4.2 & 4.2 & 91.6 & - \\
\hline & Akkeshi intertidal & $\mathrm{AI}$ & 52 & 0 & 0 & 100 & - & 52 & 0 & 0 & 100 & - & 52 & 0 & 0 & 100 & - \\
\hline \multirow[t]{2}{*}{ North } & Lake Notoro inner & LNI & 42 & 2.4 & 61.9 & 37.7 & * & 42 & 23.8 & 59.5 & 38.1 & $*$ & 42 & 2.6 & 63.2 & 34.2 & $*$ \\
\hline & Saruru & $\mathrm{SR}$ & 20 & 80 & 5 & 15 & $\star$ & 20 & 80 & 5 & 15 & $\star$ & 20 & 80 & 5 & 15 & $\star$ \\
\hline \multicolumn{18}{|l|}{2006} \\
\hline \multirow[t]{8}{*}{ West } & Hamamasu & HA & 29 & 100 & 0 & 0 & - & 25 & 100 & 0 & 0 & - & 28 & 100 & 0 & 0 & - \\
\hline & Yoichi Cape & $\mathrm{YO}$ & 98 & 100 & 0 & 0 & - & 98 & 100 & 0 & 0 & - & 95 & 100 & 0 & 0 & - \\
\hline & Furubira & FR & 50 & 100 & 0 & 0 & - & 40 & 100 & 0 & 0 & - & 48 & 100 & 0 & 0 & - \\
\hline & Kamoenai & KA & 116 & 100 & 0 & 0 & - & 105 & 100 & 0 & 0 & - & 92 & 100 & 0 & 0 & - \\
\hline & Suttsu & $\mathrm{SU}$ & 104 & 100 & 0 & 0 & - & 102 & 100 & 0 & 0 & - & 94 & 100 & 0 & 0 & - \\
\hline & Motoura & $\mathrm{MO}$ & 100 & 100 & 0 & 0 & - & 97 & 100 & 0 & 0 & - & 93 & 100 & 0 & 0 & - \\
\hline & Kaminokuni & $\mathrm{KM}$ & 105 & 100 & 0 & 0 & - & 104 & 100 & 0 & 0 & - & 78 & 100 & 0 & 0 & - \\
\hline & Fukushima & FK & 78 & 100 & 0 & 0 & - & 75 & 98.7 & 1.3 & 0 & - & 56 & 100 & 0 & 0 & - \\
\hline \multirow[t]{9}{*}{ South } & Toi & $\mathrm{TI}$ & 36 & 77.8 & 13.9 & 8.3 & $\star$ & 35 & 71.4 & 20 & 8.6 & ns & 34 & 79.4 & 14.7 & 5.9 & ns \\
\hline & Toyako Town & TY & 123 & 35 & 56.9 & 8.3 & ns & 119 & 31.1 & 53.8 & 15.1 & ns & 96 & 39.6 & 51 & 9.4 & ns \\
\hline & Muroran & MR & 102 & 33.3 & 64.7 & 2 & $*$ & 101 & 27 & 67 & 6 & $*$ & 85 & 40 & 56.5 & 3.5 & $*$ \\
\hline & Tomakomai & TO & 105 & 32.4 & 66.7 & 1 & $*$ & 103 & 33.7 & 62.5 & 3.9 & $*$ & 94 & 40.4 & 58.5 & 1.1 & $*$ \\
\hline & Niikappu & NP & 101 & 27.7 & 69.3 & 3 & $*$ & 99 & 26.3 & 72.7 & 1 & $*$ & 99 & 28.3 & 70.7 & 1 & $*$ \\
\hline & Shoya & SY & 33 & 9.1 & 72.7 & 18.2 & * & 33 & 9.1 & 72.7 & 18.2 & * & 33 & 9.1 & 72.7 & 18.2 & $*$ \\
\hline & Akkeshi subtidal & AS & 12 & 8.3 & 41.7 & 50 & - & 12 & 8.3 & 41.7 & 50 & - & 10 & 10 & 40 & 50 & - \\
\hline & Akkeshi intertidal & AI & 98 & 1 & 4.1 & 94.9 & - & 97 & 1 & 3.1 & 95.9 & - & 79 & 1.2 & 3.7 & 95.1 & - \\
\hline & Nemero & $\mathrm{NE}$ & 101 & 0 & 2 & 98 & - & 101 & 0 & 4 & 96 & - & 86 & 0 & 2.3 & 97.7 & - \\
\hline \multirow[t]{8}{*}{ North } & Utoro & UT & 98 & 55.1 & 21.4 & 23.5 & $\star$ & 98 & 51 & 26.5 & 22.5 & $\star$ & 98 & 55.1 & 23.5 & 21.4 & $\star$ \\
\hline & Abashiri & $\mathrm{AB}$ & 185 & 3.2 & 3.8 & 93 & - & 185 & 1.6 & 4.9 & 93.5 & - & 168 & 3.6 & 4.2 & 92.6 & - \\
\hline & Lake Notoro outer & LNO & 87 & 81.5 & 0 & 18.5 & $\star$ & 53 & 79.1 & 2.2 & 18.7 & $\star$ & 69 & 78.1 & 0 & 21.9 & $\star$ \\
\hline & Lake Notoro mouth & LNM & 39 & 71.8 & 5.1 & 23.1 & $\star$ & 39 & 74.4 & 2.6 & 23.1 & $\star$ & 40 & 72.5 & 5 & 22.5 & $\star$ \\
\hline & Lake Notoro inner & LNI & 72 & 5.1 & 70.9 & 24.1 & $*$ & 74 & 8.1 & 58.1 & 33.2 & ns & 54 & 10.7 & 55.4 & 33.9 & ns \\
\hline & Saruru & $\mathrm{SR}$ & 76 & 64.2 & 12.3 & 23.5 & $\star$ & 73 & 62.7 & 12 & 25.3 & $\star$ & 70 & 58.5 & 13.8 & 27.7 & $\star$ \\
\hline & Hamatonbetsu & HM & 54 & 88.9 & 3.7 & 7.4 & - & 54 & 94.4 & 0 & 5.6 & - & 51 & 94.1 & 0 & 5.9 & - \\
\hline & Sarufutsu & SA & 47 & 76.6 & 10.6 & 12.8 & $\star$ & 50 & 87.2 & 6.4 & 6.4 & $\star$ & 43 & 83.7 & 9.3 & 7 & $\star$ \\
\hline
\end{tabular}


Table 2. Mytilus galloprovincialis. Allele frequency by size classes for all 3 nuclear loci (Glu-5', MAL-I and ITS) for individuals collected around Hokkaido, Japan, in May 2006. Only populations showing significant allele frequency difference in reference to size for at least 1 locus are shown. Total number of alleles present in each size class is indicated in parenthesis. -: no individuals collected in that size class; ${ }^{*}$ : significant differences in allele frequency $(\mathrm{p}<0.05)$. G: $G$-test of independence. See Table 1 for site abbreviations

\begin{tabular}{|c|c|c|c|c|c|c|c|c|c|c|c|c|c|}
\hline \multirow{2}{*}{ Site } & \multirow{2}{*}{ Locus } & \multicolumn{11}{|c|}{ Size class $(\mathrm{mm})$} & \multirow[t]{2}{*}{$G$} \\
\hline & & $0-5$ & $5-10$ & $10-15$ & $15-20$ & $20-25$ & $25-30$ & $30-35$ & $35-40$ & $40-45$ & $45-50$ & $50-55$ & \\
\hline \multirow[t]{3}{*}{ TI } & Glu-5' & $0.75(28)$ & $0.94(34)$ & $0.72(46)$ & $0.97(35)$ & $0.97(36)$ & $0.94(18)$ & $0.92(24)$ & - & - & - & - & $22.89^{*}$ \\
\hline & ITS & $0.33(6)$ & $0.80(10)$ & $0.78(18)$ & $0.86(22)$ & $1.00(22)$ & $1.00(6)$ & $0.85(20)$ & - & - & - & - & $18.15^{*}$ \\
\hline & $M A L-I$ & $0.50(4)$ & $0.83(12)$ & $0.71(14)$ & $0.94(22)$ & $0.96(26)$ & $0.93(14)$ & $0.92(24)$ & - & - & - & - & 10.69 \\
\hline \multirow[t]{3}{*}{ TY } & Glu-5' & $0.60(42)$ & $0.61(38)$ & $0.83(40)$ & $0.77(22)$ & $0.56(36)$ & $0.59(34)$ & $0.53(34)$ & - & - & - & - & 12.20 \\
\hline & ITS & $0.42(36)$ & $0.58(36)$ & $0.76(40)$ & $0.99(18)$ & $0.53(34)$ & $0.56(34)$ & $0.50(32)$ & - & - & - & - & $24.14^{*}$ \\
\hline & $M A L-I$ & $0.63(24)$ & $0.56(34)$ & $0.85(40)$ & $0.77(22)$ & $0.61(36)$ & $0.56(18)$ & $0.50(18)$ & - & - & - & - & 13.49 \\
\hline \multirow[t]{3}{*}{ SA } & Glu-5' & - & $0.90(20)$ & $0.89(52)$ & $0.59(22)$ & - & - & - & - & - & - & - & $8.90^{*}$ \\
\hline & ITS & - & $0.90(20)$ & $0.94(52)$ & $0.82(22)$ & - & - & - & - & - & - & - & 2.53 \\
\hline & $M A L-I$ & - & $0.90(20)$ & $0.92(50)$ & $0.75(16)$ & - & - & - & - & - & - & - & 2.95 \\
\hline \multirow[t]{3}{*}{ SR } & Glu-5' & - & $0.99(77)$ & $0.56(54)$ & $0.27(30)$ & - & - & - & - & - & - & - & $74.78^{*}$ \\
\hline & ITS & - & $0.99(62)$ & $0.56(55)$ & $0.27(30)$ & - & - & - & - & - & - & - & $66.18^{*}$ \\
\hline & $M A L-I$ & - & $0.98(53)$ & $0.57(54)$ & $0.27(30)$ & - & - & - & - & - & - & - & $56.48^{*}$ \\
\hline \multirow[t]{3}{*}{ LNO } & Glu-5' & $0.94(32)$ & $0.89(104)$ & $0.58(48)$ & - & - & - & - & - & - & - & - & $21.56^{*}$ \\
\hline & ITS & $0.93(32)$ & $0.89(104)$ & $0.54(48)$ & - & - & - & - & - & - & - & - & $25.74^{*}$ \\
\hline & $M A L-I$ & $0.92(24)$ & $0.87(74)$ & $0.58(48)$ & - & - & - & - & - & - & - & - & $17.19^{*}$ \\
\hline \multirow[t]{3}{*}{ LNI } & Glu-5' & - & - & - & - & $0.27(22)$ & $0.13(24)$ & $0.20(10)$ & $0.56(16)$ & $0.50(22)$ & $0.53(30)$ & $0.50(34)$ & $18.41^{*}$ \\
\hline & ITS & - & - & - & - & $0.27(22)$ & $0.05(22)$ & $0.20(10)$ & $0.50(16)$ & $0.56(18)$ & $0.39(28)$ & $0.47(34)$ & $20.65^{*}$ \\
\hline & $M A L-I$ & - & - & - & - & $0.27(22)$ & $0.13(24)$ & $0.20(10)$ & $0.63(16)$ & $0.60(10)$ & $0.50(4)$ & $0.50(22)$ & $17.83^{*}$ \\
\hline \multirow[t]{3}{*}{ UT } & Glu-5' & - & $0.94(70)$ & $0.83(46)$ & $0.40(20)$ & $0.30(10)$ & $0.22(18)$ & $0.31(32)$ & - & - & - & - & $80.63^{*}$ \\
\hline & ITS & - & $0.94(70)$ & $0.78(46)$ & $0.35(20)$ & $0.40(10)$ & $0.17(18)$ & $0.31(32)$ & - & - & - & - & $81.33^{*}$ \\
\hline & $M A L-I$ & - & $0.94(64)$ & $0.87(52)$ & $0.40(20)$ & $0.40(10)$ & $0.22(18)$ & $0.32(32)$ & - & - & - & - & $78.84^{*}$ \\
\hline
\end{tabular}

ern and southern hybrid populations. The Kuril Islands also separate the northeastward flow of the East Sakhalin Current (ESC) from the southwestward flow of the Oyashiro Cold Current (OCC); consequently, transport across the Kuril Islands between Okhotsk Sea and the Pacific Ocean is likely minimal (Kono 1997) and seasonally dependent (Ohshima et al. 2002). Given the different genetic structure of hybrid mussel populations in northern and southern Hokkaido and their probable oceanographic isolation we conclude that these represent 2 separate hybrid zones.

It is possible that, following its introduction, Mytilus galloprovincialis displaced and may be continuing to displace $M$. trossulus. Thus, the distribution of these 2 species and their hybrid zones may still be in flux and consequently the former may not relate to any environmental variable. We find this possibility unlikely. Blue mussels were first recorded in Honshu, near Hiroshima, in 1934 (Ishida et al. 2005). Blue mussels subsequently spread rapidly throughout Honshu (Ishida et al. 2005) where they have become a prevalent part of the marine fauna. Wilkins et al. (1983) first identified these invasive mussels to be M. galloprovincialis. All subsequent samples of blue mussel from Honshu have been confirmed to be M. galloprovincialis. Thus, M. galloprovincialis rapidly invaded Honshu and other portions of the Sea of Japan. In contrast,

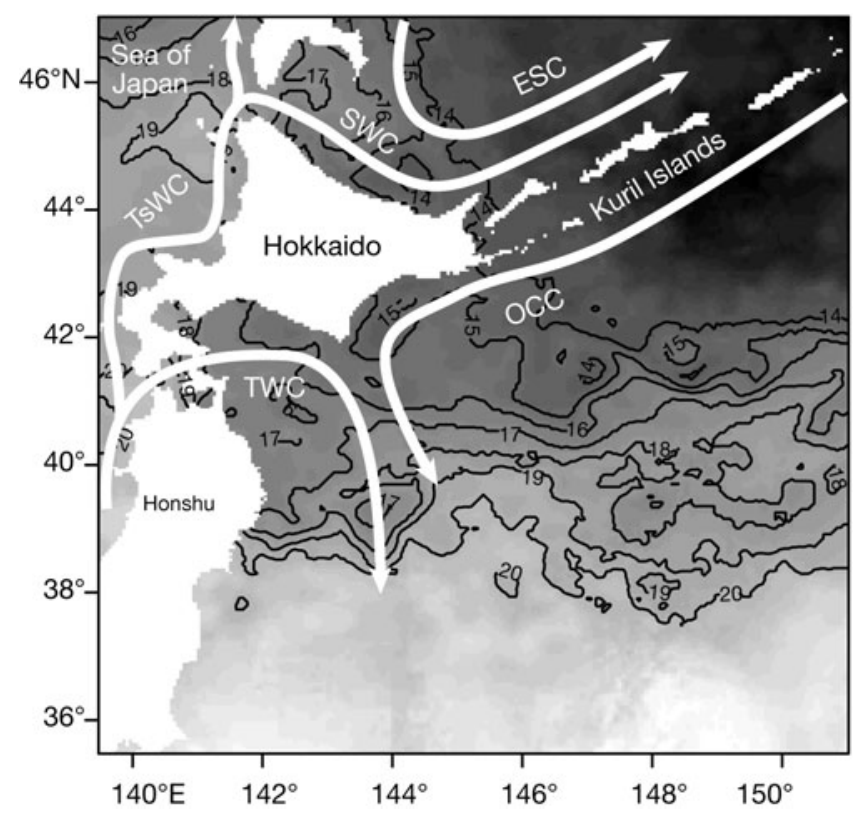

Fig. 3. Coastal currents influencing the northern and southern Hokkaido coastline, with sea surface temperature (SST) contours for 12 July 2006. SST data were obtained from the New Generation Sea Surface Temperature (NGSST) Development Group from Tohoku University (Kawamura 2008). TsWC: Tsushima Warm Current; SWC: Soya Warm Current; ESC: East Sakhalin Current; TWC: Tsugaru Warm Current; OCC: Oyashiro Cold Current 
blue mussels were reported prior to 1919 from Hokkaido and, based upon morphology, these specimens were confirmed to be $M$. trossulus (Wilkins et al. 1983). Subsequent genetic studies have confirmed that M. trossulus does not occur south of Hokkaido (McDonald et al. 1991, Inoue et al. 1997, Suchanek et al. 1997). Inoue et al. (1997) concluded, and we concur, that given the close proximity of Hokkaido and Honshu and the large volume of maritime traffic between the 2 islands, it seems likely that Hokkaido is the southern limit of $M$. trossulus in the northwest Pacific. In addition, the position of the hybrid zone between M. trossulus and M. galloprovincialis in southern Hokkaido appears to have been relatively stable for at least a decade. Inoue et al. (1997) reported the presence of hybrid mussels from 3 locations within the present position of the hybrid zone in southern Hokkaido. Thus, it appears that the present distribution of M. galloprovincialis, $M$. trossulus and their hybrids has been in place for a substantial period of time. Thus, it is likely that environmental factors determine the biogeography of these species and the position of the 2 hybrid zones in Hokkaido.

The distribution of the 2 species is correlated with sea surface temperature (SST). Mytilus galloprovincialis predominates in the Sea of Japan, which is generally warmer than the waters surrounding eastern Hokkaido. On the other hand, M. trossulus is found in portions of the western side of the Sea of Japan (Ivanova \& Lutaenko 1998, Skurikhina et al. 2001), and we found M. galloprovincialis in northern Hokkaido where SST is seasonally very cold and sea ice regularly forms during the winter (Fukamachi et al. 2006, Ohshima et al. 2006). Thus, while the distribution of the 2 species is roughly correlated with SST, it is unclear whether and how temperature may control their distribution.

The distribution and structure of the 2 hybrid zones, however, appear to be related to the complex coastal circulation patterns around Hokkaido. In the south, the Tsugaru Warm Current (TWC) flows eastward through the Tsugaru Strait between the islands of Hokkaido and Honshu (Ohshima 1994, Rosa et al. 2007) (Fig. 3). The OCC travels southwestward along the eastern coast of the Kuril Island chain to contact the southeastern coast of Hokkaido (Kono 1997) (Fig. 3). This circulation pattern establishes a gradient of warm water in the western portion of southern Hokkaido to cold water in the eastern portion of the coast. These currents also provide vectors of transport of Mytilus galloprovincialis from the Sea of Japan and M. trossulus from the Kuril Islands, where this species is prevalent (Wilkins et al. 1983, Kawahara 2001), to the southern coast of Hokkaido. The TWC and OCC converge at Cape Erimo (near SY) and are deflected to the south away from the coast (Conlon 1982, Rosa et al. 2007), which likely explains the noticeable shift in frequency of $M$. galloprovincialis and $M$. trossulus individuals observed around Cape Erimo (Figs. 1 \& 2). With these data it is not possible to separate the roles of the SST gradient from the directional physical transport in establishing the structure of the southern hybrid zone, but it does seem likely that coastal circulation plays a significant role in its architecture.

Similarly, coastal circulation patterns likely contribute to the mosaic genetic pattern observed in the northern hybrid zone. In this region, the ESC transports cold water southward down the eastern coast of Sakhalin Island which is displaced eastward by the Soya Warm Current (SWC) traveling eastward through the Soya Strait between Hokkaido and Sakhalin Island (Watanabe 1963, Ohshima 1994) (Fig. 3). The interaction of the 2 currents causes turbulent mixing along the northern coast of Hokkaido until the conjoined currents flow northward along the western margin of the Kuril Islands (Fig. 3). The 2 currents likely transport mussels from different sources, Mytilus galloprovincialis from the Sea of Japan and M. trossulus from Sakhalin Island (Wilkins et al. 1983), and the turbulent mixing of these currents likely contributes to the mosaic structure of the hybrid zone in northern Hokkaido (Figs. 1 \& 2). Again, whether this is due to the formation of a mosaic distribution of thermal habitats, heterogeneous mixing of larvae from different sources or both cannot be determined with data from the present study.

The Northern and Southern Hokkaido hybrid zones both have low frequencies of other hybrids, similar to previous reports of low levels of introgression in contact zones between Mytilus galloprovincialis and $M$. trossulus (Rawson et al. 1999, Anderson et al. 2002). However, the hybrid zones in Hokkaido differ markedly from each other in the observed frequency of $F_{1}$ hybrids. The northern hybrid zone, with exception of LNI, exhibited heterozygote deficits in every population (Table 1) and low frequencies of $F_{1}$ hybrids (Figs. 1 \& 2). In stark contrast, populations in the southern hybrid zone exhibited exceptionally high levels of hybridization with the frequency of $F_{1}$ hybrids frequently exceeding $50 \%$ (Figs. 1 \& 2) and typically contain far more heterozygous individuals than expected under HWE (Table 1, Fig. 4). This level of hybridization is several times greater than levels reported from other locations (Fig. 4). Previous studies on hybrid populations from the northeast Pacific have reported on average 10 to $20 \%$ hybridization between M. galloprovincialis and M. trossulus (McDonald \& Koehn 1988, Sarver \& Foltz 1993, Rawson et al. 1999). A few cases of hybridization levels exceeding these ranges have been reported in the northeast Pacific (Anderson et al. 2002, Wonham 2004, Schneider \& Helmuth 2007), but these 


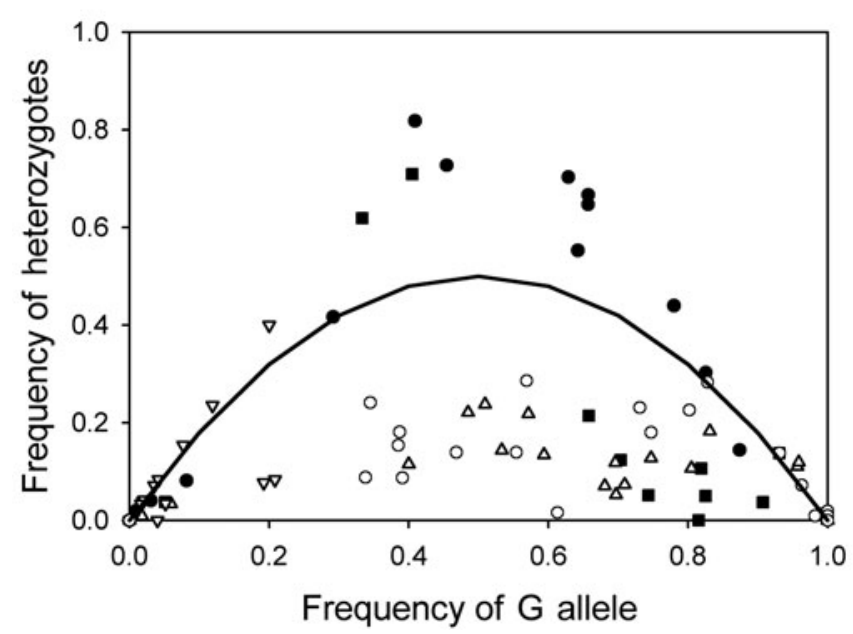

Fig. 4. Mytilus galloprovincialis. Comparison of the frequency of $M$. galloprovincialis $(\mathrm{G})$ alleles in relation to the frequency of heterozygotes for populations collected around Hokkaido, Japan (-: southern hybrid zone; $\mathbf{~ : ~ n o r t h e r n ~ h y b r i d ~ z o n e ) , ~ t o ~}$ previously reported data from the northeast Pacific $(\triangle$ : Rawson et al. 1999; O: Braby \& Somero 2006) and within Puget Sound ( $\nabla$ : Anderson et al. 2002). Data represents frequencies at the Glu-5' locus except Braby \& Somero (2006), where plotted heterozygote frequency represents the average for Glu-5' and ITS loci. - : expected frequencies of heterozygotes under Hardy-Weinberg equilibrium for all possible M. galloprovincialis allele frequencies

are rare and isolated incidences and do not reach the levels seen in Hokkaido. Hybrid zones in California and the Puget Sound generally have frequencies of heterozygous individuals that are far below HWE (Fig. 4), which results from these populations being largely composed of mixtures of the 2 parent species.

The exceptionally high levels of hybridization observed in populations around southern Hokkaido suggests the presence of a hybrid swarm with relatively free interbreeding which would lead to virtually every individual being the result of some type of mating among hybrids. This, however, is not the case; the vast majority of hybrids are heterozygous at all 3 nuclear genes, consistent with their being $F_{1}$ hybrids. The low frequency of other hybrid genotypes found around Hokkaido is consistent with that observed in the Mytilus galloprovincialis and $M$. trossulus hybrid zones in California and Puget Sound (Rawson et al. 1999, Anderson et al. 2002). Thus, the unique feature of the 2 hybrid zones in Hokkaido is the exceptionally high numbers of $F_{1}$ hybrids without the apparent free intercrossing found in some hybrid swarms between other pairs of species of Mytilus (e.g. Wilhelm \& Hilbish 1998).

Why is the frequency of $F_{1}$ hybrids in southern Hokkaido so much greater than observed in other locations where Mytilus galloprovincialis and M. trossulus are sympatric? There are 2 general possibilities: enhanced outcrossing and $F_{1}$ hybrid vigor. If mating between the 2 species is more likely than mating within a species this would generate an excess of $F_{1}$ hybrids in the progeny. It would require exceptionally strong outcrossing to produce the high frequency of $F_{1}$ hybrids observed in some populations in southern Hokkaido. At NP, for example, approximately $75 \%$ of all progeny would have to have been produced by interspecific crosses to account for the observed frequency of $F_{1}$ hybrids. Alternatively, strong preferential survival of individuals with $F_{1}$ hybrid genotypes (hybrid vigor) is another possible explanation for the extremely high levels of hybridization observed between M. galloprovincialis and M. trossulus in southern Hokkaido. Matson et al. (2003), however, did not observe any evidence of $\mathrm{F}_{1}$ hybrid vigor for growth or survival of larvae produced by crossing $M$. galloprovincialis and $M$. trossulus. Regardless of whether outcrossing and/or hybrid vigor generate such high frequency of $F_{1}$ hybrid genotypes in these populations, the mechanism(s) must be environmentally dependent because extremely high frequencies of $\mathrm{F}_{1}$ hybrid genotypes have not been observed in other hybrid zones between these 2 species.

Despite the high frequency of $\mathrm{F}_{1}$ hybrids observed in populations in southern Hokkaido, the frequency of other hybrid genotypes is very low, similar to that observed in other populations, suggesting that either $\mathrm{F}_{1}$ hybrids have relatively low fertility and consequently $\mathrm{F}_{2}$ and backcross hybrids are rarely formed, or individuals with other hybrid genotypes have poor survival (hybrid breakdown). Both mechanisms have been widely documented in other hybrid zones (Harrison 1993), but neither has been reported in mussels. Testing these hypotheses will require detailed analyses of the propensity of Mytilus galloprovincialis and M. trossulus to interbreed in Hokkaido and the relative vigor and reproductive potential of $\mathrm{F}_{1}$ and other hybrid progeny.

Acknowledgements. We thank K. R. Schneider and S. Woodin for their assistance with field work. We also thank K. Jones and J. Mazloom for their help in the laboratory. We are grateful to Y. Kuwahara for his insightful information and assistance while in Japan. We are also grateful to F. P. Lima for assistance in making the figures. We also appreciate the critical comments made by anonymous reviewers that improved the quality of this paper. This research was funded by NASA (NNG04GE43G and NNX07AF20G) and NOAA (NA04NOS4780264).

\section{LITERATURE CITED}

Anderson AS, Bilodeau AL, Gilg MR, Hilbish TJ (2002) Routes of introduction of the Mediterranean mussel (Mytilus galloprovincialis) to Puget Sound and Hood Canal. J Shellfish Res 21:75-79 
Avise JC (2004) Molecular markers, natural history, and evolution. Sinauer Associates, Sunderland, MA

Bierne N, David P, Boudry P, Bonhomme F (2002) Assortative fertilization and selection at larval stage in the mussels Mytilus edulis and M. galloprovincialis. Evolution 56: 292-298

Braby CE, Somero GN (2006) Ecological gradients and relative abundance of native (Mytilus trossulus) and invasive (Mytilus galloprovincialis) blue mussels in the California hybrid zone. Mar Biol 148:1249-1262

Carlton JT (1992) Introduced marine and estuarine molluscs of North America: an end of the 20th century perspective. J Shellfish Res 11:489-505

> Comesaña AS, Toro JE, Innes DJ, Thompson RJ (1999) A molecular approach to the ecology of a mussel (Mytilus edulis-M. trossulus) hybrid zone on the east coast of Newfoundland, Canada. Mar Biol 133:213-221

Conlon DM (1982) On the outflow modes of the Tsugaru Water Current. La Mer 20:60-64

Daguin C, Borsa P (2000) Genetic relationships of Mytilus galloprovincialis Lamark populations worldwide: evidence from nuclear-DNA markers. In: Harper EM, Taylor JD, Crane JA (eds) The evolutionary biology of the Bivalvia. Geological Society Spec Publ No. 177, Geological Society, Bath, p 389-397

Fukamachi Y, Mizuta G, Ohshima KI, Toyota T, Kimura N, Wakatsuchi M (2006) Sea ice thickness in the southwestern Sea of Okhotsk revealed by a moored iceprofiling sonar. J Geophys Res 111, C09018, doi:10.1029/ 2005JC003327

Gardner JPA, Skibinski DOF (1988) Historical and sizedependent genetic variation in hybrid mussel populations. Heredity 61:93-105

Geller JB, Carlton JT, Powers DA (1994) PCR-based detection of mtDNA haplotypes of native and invading mussels on the northeastern Pacific coast: latitudinal pattern of invasion. Mar Biol 119:243-249

Grant V (1971) Plant speciation. Columbia University Press, New York

> Grant WS, Cherry MI (1985) Mytilus galloprovincialis Lmk in Southern Africa. J Exp Mar Biol Ecol 90:179-191

Harrison RG (1993) Hybrid zones and the evolutionary process. Oxford University Press, New York

> Heath DD, Rawson PD, Hilbish TJ (1995) PCR-based nuclear markers identify introduced Mytilus edulis genotypes in British Columbia. Aquaculture 137:51

Hilbish TJ, Mullinax A, Dolven SI, Meyer A, Koehn RK, Rawson PD (2000) Origin of the antitropical distribution pattern in marine mussels (Mytilus spp.): routes and timing of transequatorial migration. Mar Biol 136:69-77

Inoue K, Waite JH, Matsuoka M, Odo S, Harayama S (1995) Interspecific variations in adhesive protein sequences of Mytilus edulis, M. galloprovincialis, and M. trossulus. Biol Bull 189:370-375

Inoue K, Odo S, Noda T, Nakao S and others (1997) A possible hybrid zone in the Mytilus edulis complex in Japan revealed by PCR markers. Mar Biol 128:91-95

Ishida S, Iwasaki K, Kuwahara Y (2005) Initial invasion history and process range extension of Mytilus galloprovincialis inferred from specimens collected by T. Furukawa. Venus 64:151-159

Ivanova MB, Lutaenko AK (1998) On the distribution of Mytilus galloprovincialis Lamarck, 1819 (Bivalvia, Mytilidae) in Russian Far Eastern seas. Bull Inst Malacol Tokyo 3:67-71

Kawahara Y (2001) Mytilus trossulus and M. galloprovincialis in Hokkaido, Japan. In: Kajiwara T, Okutani T (eds) Black intruders: frontier studies of sessile bivalves. KouseishaKouseikaku Press, Tokyo, p 7-26 (In Japanese)

Kawamura H (2008) New generation sea surface temperature for Open Ocean Ver.1.0, real-time demonstration operation. Available at www.ocean.caos.tohoku.ac.jp/ merge/ sstbinary/actvalbm.cgi

Kijewski TK, Zbawicka M, Vainola R, Wenne R (2006) Introgression and mitochondrial DNA heteroplasmy in the Baltic populations of mussels Mytilus trossulus and Mytilus edulis. Mar Biol 149:1371-1385

- Kono T (1997) Modification of the Oyashio Water in the Hokkaido and Tohoku areas. Deep-Sea Res I 44:669-688

Lee SY, Morton BS (1985) The introduction of the Mediterranean mussel Mytilus galloprovincialis into Hong Kong. Malacol Rev 18:107-109

Lowe S, Browne M, Boudjelas S, De Poorter M (2000) 100 of the world's worst invasive alien species. A selection from the Global Invasive Species Database. IUCN, Hollands Printing, Auckland

Mallet J (2005) Hybridization as an invasion of the genome. Trends Ecol Evol 20:229-237

Matson SE, Davis JP, Chew KK (2003) Laboratory hybridization of the mussels, Mytilus trossulus and M. galloprovincialis: larval growth, survival and early development. J Shellfish Res 22:423-430

McDonald JH, Koehn RK (1988) The mussels Mytilus galloprovincialis and Mytilus trossulus on the Pacific Coast of North America. Mar Biol 99:111-118

> McDonald JH, Seed R, Koehn RK (1991) Allozymes and morphometric characters of three species of Mytilus in the Northern and Southern Hemispheres. Mar Biol 111: 323-333

Nason JD, Ellstrand NC (1993) Estimating the frequencies of genetically distinct classes of individuals in hybridized populations. J Hered 84:1-12

Ohshima KI (1994) The flow system in the Japan Sea caused by a sea-level difference through shallow straits. J Geophys Res C Oceans 99:9925-9940

> Ohshima KI, Wakatsuchi M, Fukamachi Y, Mizuta G (2002) Near-surface circulation and tidal currents of the Okhotsk Sea observed with satellite-tracked drifters. J Geophys Res C Oceans 107:3195-3212

> Ohshima KI, Nihashi S, Hashiya E, Watanabe T (2006) Interannual variability of sea ice area in the Sea of Okhotsk: importance of surface heat flux in fall. J Meteorol Soc Jpn 84:907-919

Rawson PD, Hilbish TJ (1995) Evolutionary relationships among the male and female mitochondrial-DNA lineages in the Mytilus edulis species complex. Mol Biol Evol 12: 893-901

Rawson PD, Hilbish TJ (1998) Asymmetric introgression of mitochondrial DNA among European populations of blue mussels (Mytilus spp.). Evolution 52:100-108

Rawson PD, Joyner KL, Meetze K, Hilbish TJ (1996a) Evidence for intragenic recombination within a novel genetic marker that distinguishes mussels in the Mytilus edulis species complex. Heredity 77:599-607

Rawson PD, Secor CL, Hilbish TJ (1996b) The effects of natural hybridization on the regulation of doubly uniparental mtDNA inheritance in blue mussels (Mytilus spp.). Genetics 144:241-248

Rawson PD, Agrawal V, Hilbish TJ (1999) Hybridization between the blue mussels Mytilus galloprovincialis and $M$. trossulus along the Pacific coast of North America: evidence for limited introgression. Mar Biol 134:201-211

Rawson PD, Hayhurst S, Vanscoyoc B (2001) Species composition of blue mussel populations in the northeastern Gulf 
of Maine. J Shellfish Res 20:31-38

Rawson PD, Slaughter C, Yund PO (2003) Patterns of gamete incompatibility between the blue mussels Mytilus edulis and M. trossulus. Mar Biol 143:317-325

Rice WR (1989) Analyzing tables of statistical tests. Evolution 43:223-225

Riginos C, Cunningham CW (2005) Local adaptation and species segregation in two mussel (Mytilus edulis $\times$ Mytilus trossulus) hybrid zones. Mol Ecol 14:381-400

Rosa AL, Isoda Y, Uehara K, Aiki T (2007) Seasonal variations of water system distribution and flow patterns in the southern sea area of Hokkaido, Japan. J Oceanogr 63: 573-588

Sarver SK, Foltz DW (1993) Genetic population structure of a species complex of blue mussels (Mytilus spp.). Mar Biol 117:105-112

Schneider KR, Helmuth B (2007) Spatial variability in habitat temperature may drive patterns of selection between an invasive and native mussel species. Mar Ecol Prog Ser 339:157-167

Seed R (1992) Systematics evolution and distribution of mussels belonging to the genus Mytilus: an overview. Am Malacol Bull 9:123-137

Skurikhina LA, Kartavtsev YF, Chichvarkhin AY, Pan'kova MV (2001) Study of two species of mussels, Mytilus trossulus and Mytilus galloprovincialis (Bivalvia, Mytilidae), and

Editorial responsibility: Philippe Borsa,

Nouméa, New Caledonia their hybrids in Peter the Great Bay of the Sea of Japan with the use of PCR markers. Russ J Genet 37:1448-1451

Sokal R, Rohlf F (1995) Biometry: the principles and practice of statistics in biological research. W. H. Freeman \& Company, New York

Suchanek TH, Geller JB, Kreiser BR, Mitton JB (1997) Zoogeographic distributions of the sibling species Mytilus galloprovincialis and M. trossulus (Bivalvia: Mytilidae) and their hybrids in the north Pacific. Biol Bull 193:187-194

Toro J, Innes DJ, Thompson RJ (2004) Genetic variation among life-history stages of mussels in a Mytilus edulis-M. trossulus hybrid zone. Mar Biol 145:713-725

Watanabe K (1963) On the reinforcement of the East Sakhalin Current preceding to the sea ice season off the coast of Hokkaido: study on sea ice in the Okhotsk Sea (IV). Oceanogr Mag 14:117-130

Wilhelm R, Hilbish TJ (1998) Assessment of natural selection in a hybrid population of mussels: evaluation of exogenous vs. endogenous selection models. Mar Biol 131:505-514

> Wilkins NP, Fujino K, Gosling EM (1983) The Mediterranean mussel Mytilus galloprovincialis Lmk in Japan. Biol J Linn Soc 20:365-374

Wonham MJ (2004) Mini-review: distribution of the Mediterranean mussel Mytilus galloprovincialis (Bivalvia: Mytilidae) and hybrids in the Northeast Pacific. J Shellfish Res 23:535-543

Submitted: November 11, 2008; Accepted: March 4, 2009 Proofs received from author(s): April 28, 2009 